\title{
Importance of experimentation on teaching the basics of optics at elementary to high school
}

Manuel Costa

Manuel F. M. Costa, "Importance of experimentation on teaching the basics of optics at elementary to high school," Proc. SPIE 3190, Fifth International Topical Meeting on Education and Training in Optics, (8 December 1997); doi: $10.1117 / 12.294388$

Event: Fifth International Topical Meeting on Education and Training in Optics, 1997, Delft, Netherlands 


\title{
The importance of experimentation on teaching the basics of optics at elementary to high school
}

\author{
Manuel F. M. Costa
}

\author{
Universidade do Minho, Departamento de Física \\ Tel. +35153 604327(311203); Fax. +35153 604339(324102) \\ Email: mfcosta@fisica.uminho.pt \\ P-4709 BRAGA CODEX PORTUGAL
}

\begin{abstract}
In 1996 the Portuguese Ministry of Science and Technology opened a scholarship program aiming the improvement and enlargement of the use of experimentation on teaching science classes in non university schools. Inscribed on that program' spirit I proposed two different projects on the theme of elementary optics teaching. In both, approved, projects I count with the active cooperation of two groups of physics (and chemistry) teachers and the respective schools (grades from 5th to 12th). Both projects had the same object and goals. However they correspond to different ways of meeting the objectives. The first project named "Light, color and vision" is located on a small village' school with a large percentage of students coming from rural areas. The actions take place mostly in the 8th grade classes of physics and chemistry, during class time and were included on teacher's class programmation. On the other hand the project "The fascination of light" takes place on a town's large high school. The experimental work sessions occur after school time and are not mandatory. A group of voluntary science students (with no age or grade limitation) was accepted to attend all sessions. However the sessions are always open to all school' students at any time. In the overall over 400 students are involved.
\end{abstract}

Keywords: Physics education, Elementary optics, Active education, Demonstrations

\section{BACKGROUND}

Above all the objective, the work of the physicist is to discover, to understand and to explain the physical world.

Observing, to see critically is the first, fundamental step in this process. The student must not only to understand this deeply, as they must to be taught to see, to observe. This should be the first concern of a physics/science teacher.

We may even argue about the interest in explaining, transmitting the concepts if the student is not able to "see" the problems, the situations and to be unable to distinguish/discriminate the processes/problems involved that need to be solved or explained in order for the situations to be understood. It is definitely of utmost importance to early teach the students to observe but also to raise questions, to perform critical analysis, to build new situations and scenarios. 
In order to captivate the students attention and interest for physics (science and technology, in general) is common practice among the most concerned teachers, to make the presentation or demonstration of some experiments as spectacular as possible. An high degree of sophistication is often sought in order to increase the impact among the generally alienated students. The problem is that it is more and more difficult to find new situations that could surpass the ones all students already saw repeatedly in TV or cinema. Furthermore they tend to accept as enough the ideas/explanations (usually inaccurate, even wrong and misleading) they receive in such a any (and they do get them selves definitely bored when attempts are made to discuss and explain those subjects). The major problem with this process is that the "information" is received fast and in an extremely passive way. They see, they ear but never critically. And in that way no meaningful knowledge can ever be attained !

So,... what to do? Lets turn into the basics. To simple things. Every day situations. Simple old fashion apparatus. And, above all, lets give time (we should never forget teaching takes time and learning takes much more!) the students to see, to discuss, to play with, to enjoy, to have fun, to feel the trill of discovery, to wonder them selves with the world of physics... Nice words!... In reality... it do pays the effort!

Increasing students' specific knowledge is important. But above all science demands work, responsibility and method. It is precisely this the most important thing the science teaching should give to the students.

Hands on, experimental work is surely be the best way to achieve those goals. Furthermore in classic lectures students have an attention span less then 15 minutes. The introduction of, even small, practical hands on activities or some practical problems to be discussed in class, do allow a much more effective extensive profit of the class time.

We can not wait that all of our students become scientists or fellows truly interested on these subjects, but it is our "obligation" to try to make that number the higher the possible ${ }^{(1-6,8)}$.

\section{INTRODUCTION}

The generic objective of the "Ciência Viva" ("Science Alive") program created in 1996 by the Portuguese Ministry of Science and Technology was to the improve and enlarge the use of experimentation on teaching science classes in secondary and primary schools.

Our specific objectives arose from the huge deficiencies in the knowledge of the even very basic concepts of optics I noticed in my classes of geometrical optics at the undergraduate course of Applied Optics (optics branch). More then one quarter of the students stated that they have not ear about optics ever in classroom (for instance in the 8th grade the optics subject is optional and most frequently not taught at all) before entering the university! Only a few students have shown an acceptable understanding of the meaning of index of refraction. However a nice number of students recognized the lens maker formulae. But... could not solve a simple minor problem with it!

Thus our first goal was to complement the formation of the secondary schools' students in the field of Elementary Optics. However our main objective rely on the lines wrote above in the introduction!

My objectives found a good receptivity among two groups of teachers of the Minho's secondary schools Alberto Sampaio (ESAS) and Vila Verde (ESVV).

Two different projects on the theme of elementary optics teaching were presented and approved. The projects had the same object and goals but correspond to different approaches to our problems. The practical hands on actions scheduled in the first project $\left(\mathrm{n}^{\circ} .153\right)$ named "Light, color and vision" should take place during 
class time (8th grade classes of physics and chemistry) and were included on teacher's class programmation. For the second project "The fascination of light" (project $n^{\circ} .218$ ) settled at the ESAS the experimental work actions are voluntary and take place after school time. A group of voluntary science students (with no age or grade limitation but mostly from the 8th grade) was accepted to attend all sessions. However the sessions were always open to all schools' students at any time. The ESAS is a relatively large secondary school of the Minho's town capital, Braga. The ESVV is located on a small village with a large percentage of students coming from rural areas.

Apart from my self that coordinate the project, six teachers and around 300 students of the ESVV were involved on project $n^{\circ}$. 153. Project $n^{\circ}$. 218 involved until the moment less then 100 students and 8 teachers of ESAS.

\section{3. “LIGHT, COLOR AND VISION"}

Lets give a fast overview of project $\mathrm{n}^{\circ} .153$.

A small set of hands on simple experiments (however with an increasing complexity) was prepared togheter with a small actions' guide ${ }^{(3-6)}$. A permanent appeal is made to an active critical posture. All of the sessions' evolution rely essentially on the observation. The students should see, discuss and get their own conclusions and whenever possible to establish what to do next. They are encouraged to step out of the guide's proposals and follow their one paths to reach the goals. Time was rather short and the students were not used to this kind of action. Thus all the actions were not fully accomplished. This was definitely not considered a major drawback. Each student has his own pace and we should also understand that. Rushing things it is not a good strategy at all.

The students begin looking and discussing different sources of light from the sun to sodium fluorescein. Light dispersion with Newton prisms was next. A short analysis of the human visual system was performed. The color vision and color matching were then introduced ${ }^{(9)}$. Several simple experiments were performed by definitely enchanted students. Some optical illusions have been observed and discussed. Next they entered the domain of the basics of geometrical optics. Simple ray tracing experiments were done. The mirrors and lenses were introduced. The microscope and the telescope become rather popular! A short contact with the diffraction concept, holography and fiber optics ended the activities.

To raise all the material needed we spent a bit more then USD2,000. The Introductory Optics kit from the Optical Society of America provided the main equipment. We just add a few diode lasers ${ }^{(6,7)}$, prisms, white light sources (in order to help the study of color addition we designed and built light source's boxes with three openings and orientable mirrors), illusions cards, plastic light guides...

\section{RESULTS}

The very positive way the project evolved on the classroom's experimental activities was confirmed by the assessment of the knowledge improvement on these matters. But, above all, the interest of this kind of actions was marked by the students opinion expressed on voluntary surveys the students filled by the end of the action. 98\% of the students was very pleased with the action and expressed their desire of seeing it continued. A important majority stressed the importance of hands on experimental work on learning physics.

Even with younger students ${ }^{(8)}$ from pre-school or elementary ( 5 to 8 years old) this kind of action have a striking positive effect. The basics of some subjects are easily understood: addition of colors (often older students take longer to understand the process because they are used to the subtractive ink's color mixing), reflection of light and internal total reflection (a piece of sweet flavored jelly may act as an wonderful... light 
guide!), refractive bending of light (the coin in the bottom of a plastic cup; a trip to a rivers' shore may become an highly productive and pleasant experience!).

Confirming what I said above in the introduction even the younger children insistently request to see and play (literally!) with lasers. Constant references are made to TV films or cartoons. Fiber optics are also mentioned and when in use they become very popular. Not only the students see that light can go from one side of the fiber to the other even if highly bender as they also realize the fiber can be used to see objects in the other end away.

To assess the long term benefits of this kind of actions is rather important and as far as we know it have not yet been done at enough extent.

We are planning to give our small contribution. A voluntary record of most of the participating students was made. We hope it allows us to track the evolution of these students up to the university. More then $85 \%$ of the student expecting to pursue an higher education, plan to go to the University of Minho. At the moment we do not expect to welcome more then $10 \%$ of these students at our undergraduate physics courses. However we hope to increase that value with future actions next to the registered students.

\section{CONCLUSION}

Perhaps more important than knowing concepts or theories is to know how to get them. Its necessary to observe, to think, to reason, to analyze critically and interactively problems and situations. More important then the final concepts, is knowing, feeling, interiorizing the paths or processes of, or to, understand them.

Once more it was clearly proven that the pursuit of experimental hands on work by the students on or off the classroom its a powerful way to helps us science teachers to reach our basic goals.

\section{ACKNOWLEDGMENT}

The author wish to express his acknowledgment to all students involved in these projects, to the Escola Secundária de Vila Verde and, for their work commitment and support, to the monitors of the project $\mathrm{n}^{\circ} .153$ Mrs. G. Freixo, M. Gama, F. Machado, V. Vieira, O. Silva, S. Reis - and to the monitors of the project $\mathbf{n}^{\circ} .218$ Mrs. A. Fernandes, E. Carvalho, M. Barbosa, M. Sousa, M. Silva, P. Baía, I. Monteiro, M. Oliveira - of the Escola Secundária de Alberto Sampaio. The author which express his esteem to Mr. A. Rodrigues, technician of the Physics Department of the University of Minho, for is unrestricted support. Finally the author wish to pay a deep compliment to the Portuguese Ministry of Science and Technology and to the Programa "Ciência Viva" by their pioneer initiative.

\section{REFERENCES}

1. Manuel F.M. Costa, “Teaching Applied Optics at the University of Minho”, Proc. Soc. Photo-Opt. Instrum. Eng. 2525, 357-361 (1995).

2. P. Narayana Swany; "Put the real world in the physics curriculum", letter, Physics Today vol. $48, \mathrm{n}^{\circ} .9$, p. 15 (1995).

3. A. S. Prasanis; "Teaching Optics in the Optics Age", Proc. Soc. Photo-Opt. Instrum. Eng. 2525, 318-330 (1995).

4. Joseph H. Schuch, Z. L Wu, "Getting students to see the light". Proc. Soc. Photo-Opt. Instrum. Eng. 2525, 309-315 (1995). 
5. M. J. Nofziger, "Optics curriculum for middle school students", Proc. Soc. Photo-Opt. Instrum. Eng. 2525, 213-224 (1995).

6. Gareth Williams, "Laser experiments for the secondary school classroom", Proc. Soc. Photo-Opt. Instrum. Eng. 2525, 230-246 (1995).

7. H. Weichel, W. A Danne, L. S. Pedrotti, "Laser safety in the laboratory", American Journal of Physics, vol. 42, 1006-1013 (1974).

8. C. Wilder, “Elementary laser optics? Yes!”, Proc. Soc. Photo-Opt. Instrum. Eng. 2525, 193-197 (1995).

9. A Visão das cores, Manuel F.M. Costa, Universidade do Minho, 1995. 